\title{
An Isolated Displaced Fracture of the Coracoid Process Treated with Osteosynthesis-A Case Report and Review of Literature
}

\author{
Adala Raviraj, Ashish Anand*, Srinivas Vijay \\ Department of Orthopaedic Surgery, Fortis Hospitals Ltd., Bangalore, India \\ Email: *ashishanandortho@yahoo.com
}

Received December 14, 2012; revised January 16, 2013; accepted January 25, 2013

\begin{abstract}
Coracoid process fractures are relatively rare and few cases have been reported in the orthopedic literature. In this article, we report the case of an active, thirty years old, male patient with isolated, displaced fracture of the coracoid process, associated with a blunt injury to the shoulder, during a motor vehicle accident. We describe the incidence, mechanism of injury, and surgical treatment. Although rare, a high index of suspicion, special radiographic views, can detect an isolated coracoid process. Knowledge of the associated injuries will help the clinician to order further imaging and treat them accordingly. We recommend that a displaced, isolated fracture of the coracoid be treated with open reduction and osteosynthesis, to achieve early use of the extremity, good radiological union and clinical function.
\end{abstract}

Keywords: Fracture Coracoid; Isolated Fracture; Associated Injuries; Osteosynthesis; Open Reduction; Internal Fixation

\section{Introduction}

Usually coracoid-fractures are “chain-injuries” in association with complex shoulder injuries. Coracoid fractures have been described as uncommon injuries [1-3]. The incidence has been assessed at between 3\% and 13\% of all scapular fractures; these constitute $1 \%$ of all fractures and $5 \%$ of those of the shoulder [4]. Isolated injuries of coracoid are a rare occurrence with few scattered reports in literature [5-7].

\section{Case Report}

An office goer, presented to our tertiary referral centre, with history of severe pain in the right infraclavicular region and difficulty in moving his right shoulder and using right upper limb. He had sustained a motor vehicle accident (MVA) three days back after his car crashed on the highway. He was initially treated at a community hospital where the shoulder $\mathrm{x}$ rays were done and he was treated with analgesics and a sling. He had no injuries in the cranium, cervical spine or chest.

The examination revealed fullness in the right infraclavicular region. He supported his right arm flexed at the elbow, with the left hand. Tenderness was elicited over the coracoid with credits on deeper palpation. All

"Corresponding author. movements of the shoulder were severely painful and were restricted. There was no distal neurovascular deficit.

The anteroposterior and axial x-ray of the shoulder showed a displaced fracture of the coracoid (Figure 1). The cervical spine and chest $\mathrm{x}$ ray were unremarkable. A CT scan with 3dimensional reconstruction of the shoulder was done to look for any associated injuries in the shoulder girdle. This showed only a displaced fracture at the base of the coracoid process without any other injuries (Figures 2 and $\mathbf{3}$ ).

\section{Surgical Technique and Post Operative Care}

Patient was placed under general anesthesia and examination of shoulder joint was done. There were no signs of instability. At this time patient was placed in a beach chair position and parts were cleaned and draped in standard orthopedic fashion. An anterior delto pectoral approach was used for exposure of the fracture site. After identifying the cephalic vein in the Deltopectoral interval and moving it laterally, the clavicpectoral fascia was divided and the coracoid process and the fracture site were identified. The coracoid fragment was found avulsed from the base with the pectoralis minor and short head of biceps attached to it. The fragment was reduced on to the 


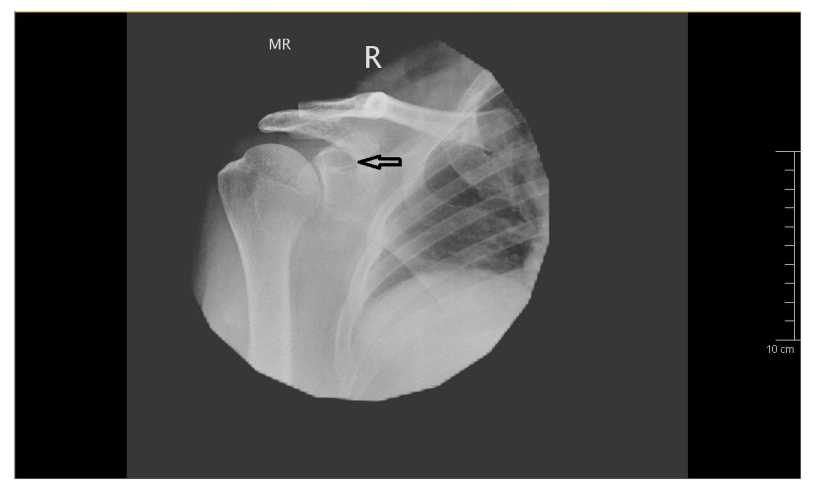

Figure 1. The radiograph showing displaced fracture of the coracoid.

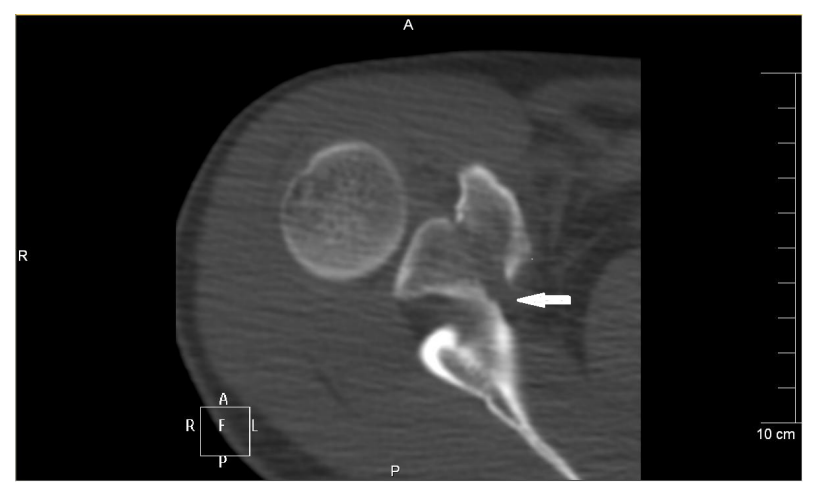

Figure 2. The CT scan image showing the displaced fracture coracoid.

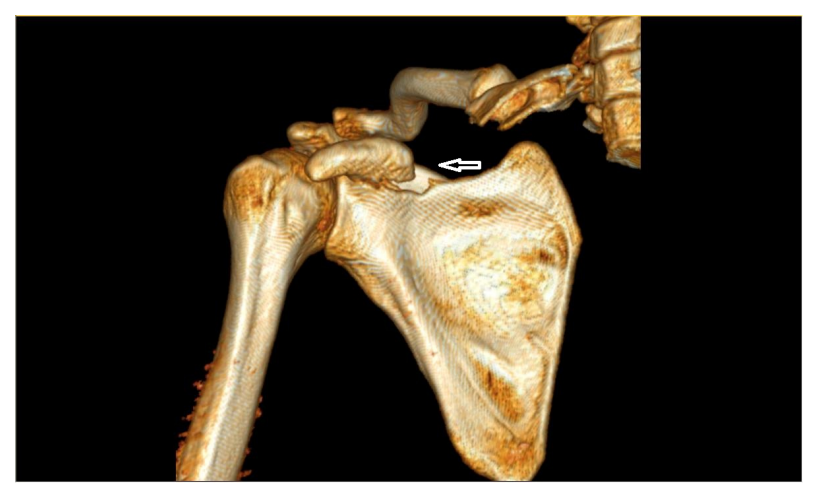

Figure 3. Three dimensional reconstruction of the CT image showing displaced fracture of the coracoid.

scapula and provisionally held with a K wire, which was placed under $\mathrm{x}$ ray guidance. The coracoclavicular and coraco acromial ligaments were found to be intact. The definitive fixation of the fragment was done with two 6 $\mathrm{mm}$ partially threaded cancellous screws with washer (Figure 4). The fixation was checked under image intensifier.

Post operatively patient was on a shoulder arm pouch with gentle shoulder move ments started from second post operative day. The post operative radiograph showed good reduction of the fracture with implants in

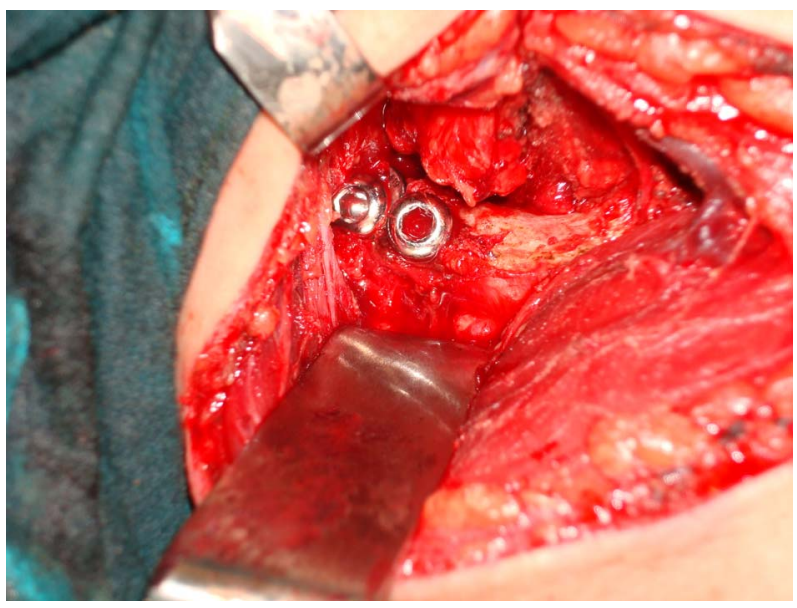

Figure 4. Intra operative picture showing the coracoids fracture fixed with two $6 \mathrm{~mm}$ cancellous screws.

situ. (Figure 5) The sutures were removed at two weeks post op. The abduction and external rotations were however commenced from third week post surgery.

The fracture went on to unite at 8 weeks post operatively and patient had achieved full range of moments of the affected shoulder. At two years follow up the fracture was found well united and clinically the patient had normal shoulder function (Figures 6 and 7).

\section{Discussion and Review of Literature}

Isolated Fractures of the coracoid occur from direct blow to the coracoid or to the point of the shoulder $[8,9]$. Coracoid fractures may occur in association with acromioclavicular dislocation with the coracoclavicular ligaments remaining intact [10-12]. The various modes of coracoid fractures include avulsion by muscle pull of biceps and coracobrachialis [13], direct contact of dislocating humeral head [14,15], fatigue fractures [16], as a complication of tape fixation of acromioclavicular joint [15] or from medial migration of humeral head from cuff arthropathy. In our patient the mechanism of injury was an injury sustained as the car he was driving toppled in a highway.

Though the exact mechanism of injury in a motor vehicle accident may be difficult to explain, the most likely mechanism is that severe muscle contraction forces by the short head of biceps and the pectoralis minor, on the coracoid process, as the person was fastened with seatbelt, have avulsed the base of the coracoid from the scapula. An indirect muscle contraction forces rather than a direct injury to the shoulder explains the absence of associated "chain injuries" with this rare injury.

Coracoid fractures can be missed on the normal routine AP view. It is best visualized by the following views Axillary View, An Anteroposterior Cephalic Tilt View, Stryker Notch view [17] and a Goldberg view [18]. 


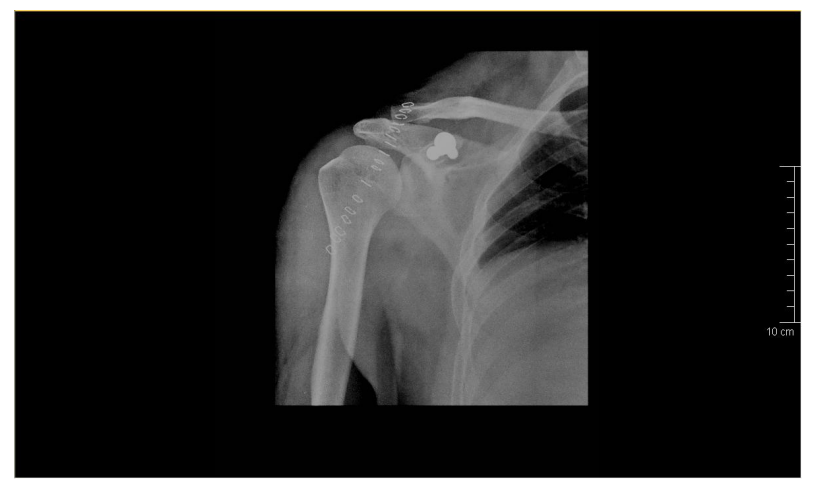

Figure 5. Post operative anteroposterior $x$-ray showing good reduction of the fracture and screws in situ.

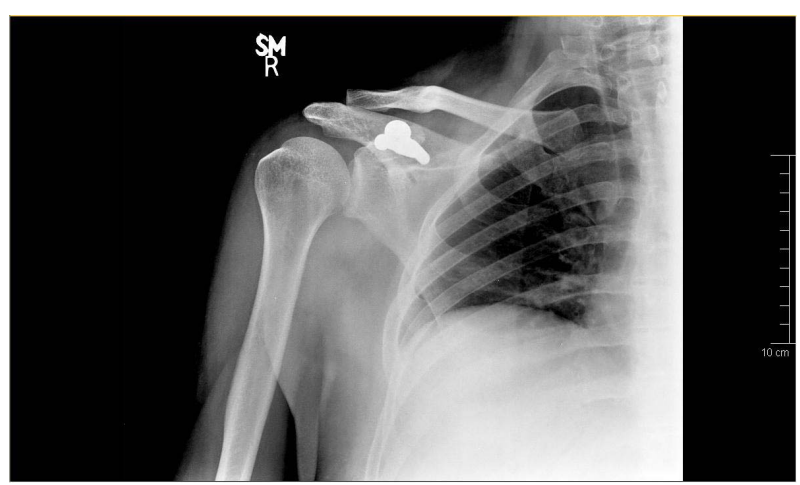

Figure 6. The anterioposterior x-ray at two years follow up showing healed fracture with internal fixation in situ.

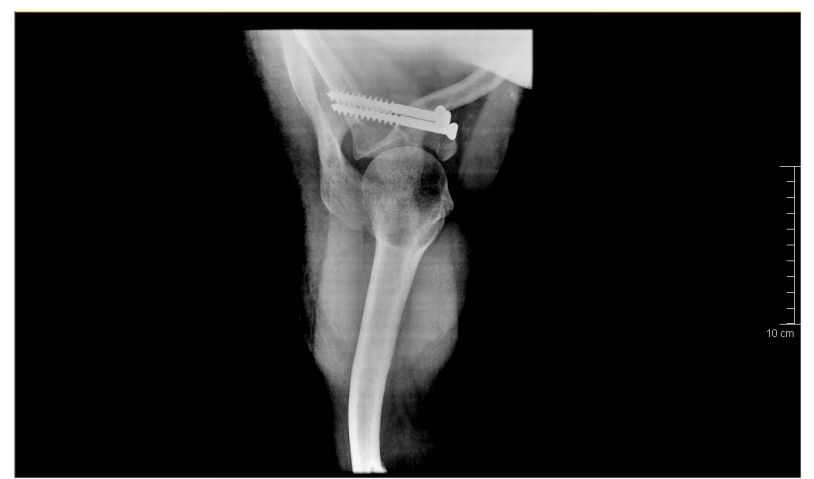

Figure 7. The Axial $x$-ray at two years follow up showing healed fracture with internal fixation in situ.

However the best investigation remains Ct scan with $3 \mathrm{~d}$ reconstruction which can show associated injuries as well. In the current situation the extent of fracture and degree of displacement was well appreciated on the 3-D CT.

The fracture sites reported in adults are: the base of the process [2], sometimes this fracture line may extend across the suprascapular notch into the upper third of glenoid [19]. The other sites include the mid substance of the coracoid [1] and the tip [3,20].

A critical review of literature suggests that the treatment modalities are dictated by the degree of displace- ment, associated injuries and location of fracture. There is near consensus that undisplaced/minimally displaced fractures of the coracoid base should be treated by conservative means [21,22]. In injuries in which coracoid base is displaced excellent results have been obtained following open reduction [23-25] The jury is divided when it comes to coracoid process injury with acromiclavicular injury with both conservative and operative treatment offering equally favorable results [8,26-28]. Wilbur [26] et al. recommend that surgery should be done if there is significant displacement and compression of brachial plexus. Eyres [29] et al. recommend that in patients with significant separation of Ac joint and displacement of coracoid both should be treated by open reduction and fixed using the transacromial threaded pin. They have also recommended that open reduction is the preferred treatment modality if fracture extends into glenoid fossa or if there is an obstruction to reduction of anterior shoulder dislocation.

OGAWA [30] et al. described 67 consecutive fractures of the coracoid in their report [8] and they classified them based on the relationship between the fracture site and the coracoclavicular ligament. Fifty three fractures were behind the ligament (type 1) and the remaining 11 fractures were front of the ligament (type 2). They described type 1 fractures were associated with a wide variety of shoulder injuries and consequent dissociation between the scapula and the clavicle. The fractures anterior to the ligament were treated conservatively. They concluded that the operative treatment should be reserved for patients with multiple shoulder injuries with severe disruption of the scapuloclavicular connection. For fractures involving the tip few authors [31,32] have recommended that the tip be excised followed by reattachment of the conjoined tendons to the remaining coracoid process.

In summary, there is no consensus about the treatment of isolated coracoid fractures. One has to adopt a la carte approach and treat every patient on a case to case basis. In our case the young adult had significant displacement; hence surgery was a reasonable option.

\section{Conclusion}

We recommend that a displaced, isolated fracture of the coracoid be treated with open reduction and osteosynthesis, to avoid immobilization of the extremity and for good radiological union and clinical function.

\section{REFERENCES}

[1] O. H. Petty, "Fracture of the Coracoid Process of the Scapula Caused by Muscular Action,” Annals of Surgery, Vol. 45, No. 3, 1907, pp. 427-430. doi:10.1097/00000658-190703000-00008 
[2] F. Caesar, "Isolierter Bruch des Rabenschnabelfortsatzes und Seine Rontgendarstellung," Fortschritte auf dem Gebiete der Rontgenstrahlen, Vol. 35, No. 5, 1926, pp. 519520.

[3] K. Horn, "Beobachtung Eines Uberlastungsschadens der Schulterblattgrate und des Proccoracoideus," Wschr Unfallheilk, Vol. 49, No. 1, 1942, pp. 53-59.

[4] M. McGinnis and J. R. Denton, "Fractures of the Scapula: A Retrospective Study of 40 Fractured Scapulae,” Journal of Trauma and Acute Care Surgery, Vol. 29, No. 11, 1989, pp. 1488-1493.

doi:10.1097/00005373-198911000-00006

[5] K. Ogawa, S. Inokuchi and K. Matsui, "Fracture of the Coracoid Process,” Acta Orthopaedica Scandinavica, Vol. 61, No. 1, 1990, pp. 7-8.

[6] K. S. Eyres, A. Brooks and D. Stanley, "Fractures of the Coracoid Process," The Journal of Bone and Joint Surgery, Vol. 77, No. 3, 1995, pp. 425-428.

[7] F'ery A, Sommelet J. Fracture of the coracoid process. Rev Chir Orthop Reparatrice Appar Mot 1979; 65:403-7.

[8] P. P. Mariani, "Isolated Fracture of the Coracoid Process in an Athlete," The American Journal of Sports Medicine, Vol. 8, No. 2, 1980, pp. 129-130. doi:10.1177/036354658000800214

[9] J. F. Gil and A. Haydar, "Isolated Injury of the Coracoid Process: Case Report,” Journal of Trauma, Vol. 31, No. 12, 1991, pp. 1696-1697. doi:10.1097/00005373-199112000-00023

[10] T. N. Bernard Jr., M. E. Brunet and R. J. Haddad Jr., “Fractured Coracoid Process in Acromioclavicular Dislocations. Report of Four Cases and Review of the Literature," Clinical Orthopaedics and Related Research, Vol. 175, No. 5, 1983, pp. 227-232.

[11] D. Herscovici Jr., A. G. Fiennes, M. Allgöwer and T. P. Rüedi, "Coracoid Fractures," Journal of Bone and Joint Surgery, Vol. 74, No. 3, 1992, pp. 362-364.

[12] J. P. Zettas and P. D. Muchnic, "Fracture of the Coracoids Process Base and Acute Acromioclavicular Separation,” Orthopedic Reviews, Vol. 5, No. 1, 1976, pp. 77-79.

[13] R. C. Rounds, "Isolated Fracture of the Coracoid Process,” Journal of Bone and Joint Surgery, Vol. 31, No. 3, 1949, p. 662.

[14] M. Garcia-Elias and J. M. Salo, "Non-Union of a Fractured Coracoid Process after Dislocation of the Shoulder. A Case Report,” Journal of Bone and Joint Surgery, Vol. 67, No. 5, 1985, pp. 722-723.

[15] M. S. Moneim and F. C. Balduini, "Coracoid Fracture as a Complication of Surgical Treatment by Coracoclavicular Tape Fixation. A Case Report," Clinical Orthopaedics and Related Research, Vol. 168, 1982, pp. 133-135.

[16] D. W. Boyer Jr., “Trapshooter's Shoulder: Stress Fracture of the Coracoid Process. Case Report," Journal of Bone and Joint Surgery, Vol. 57, No. 6, 1975, p. 862.

[17] C. A. Rockwood, "Management of Fractures of the Scapula,” Orthopaedics Transactions, Vol. 10, 1986, p. 219.

[18] R. P. Goldberg and B. Vicks, "Oblique Angled View for Coracoid Fractures,” Skeletal Radiology, Vol. 9, No. 3,
1983, pp. 195-197. doi:10.1007/BF00352554

[19] R. Ideberg, "Fractures of the Scapula Involving the Glenoid Fossa,” In: J. E. Bateman and R. P. Welsh, Eds., Surgery of the Shoulder, Decker, Philadelphia, 1984, pp. 63-66.

[20] Z. Zilberman and R. Rejovitzky, "Fracture of the Coracoid Process of the Scapula,” Injury, Vol. 13, No. 3, 1981, pp. 203-206. doi:10.1016/0020-1383(81)90239-4

[21] T. Martin-Herrero, C. Rodriguez-Merchan and L. Munuera-Martinez, "Fractures of the Coracoid Process: Presentation of Seven Cases and Review of the Literature," The Journal of Trauma and Acute Care Surgery, Vol. 30, No. 12, 1990, pp. 1597-1599. doi:10.1097/00005373-199012000-00031

[22] A. J. Carr and N. S. Broughton, “Acromioclavicular Dislocation Associated with Fracture of the Coracoid Process," The Journal of Trauma and Acute Care Surgery, Vol. 29, No. 1, 1989, pp. 125-126. doi:10.1097/00005373-198901000-00030

[23] A. S. Subramanian, M. A. Khalik and M. M. Shah, "Isolated Fracture of the Coracoid Process Associated with Unstable Shoulder,” ANZ Journal of Surgery, Vol. 77, No. 3, 2007, pp. 188-189. doi:10.1111/j.1445-2197.2006.04005.x

[24] C. Spormann, P. Holzach and C. Ryf, "[Isolated Coracoid Fracture-Open Reposition and Osteosynthesis-Report of 3 Cases],” Swiss Surgery, No. 4, 1998, pp. 198-202.

[25] J. Guiral, J. L. Real and J. M. Curto, "Isolated Fracture of the Coracoid Process of the Scapula," Acta Orthopaedica Belgica, Vol. 62, No. 1, 1996, pp. 60-61.

[26] M. C. Wilbur and E. B. Evans, "Fractures of the Scapula: An Analysis of Forty Cases and Review of Literature," The Journal of Bone and Joint Surgery, Vol. 59, No. 3, 1977, pp. 358-362.

[27] S. D. Martin and A. J. Weiland, "Missed Scapular Fracture after Trauma,” Clinical Orthopaedics, Vol. 299, 1994, pp. 259-262.

[28] D. M. Smith, "Coracoid Fracture Associated with Sternoclavicular Dislocation: A Case Report,” Clinical Orthopaedics, Vol. 108, 1975, pp. 165-167. doi:10.1097/00003086-197505000-00026

[29] K. S. Eyres, A. Brooks and D. Stanley, "Fractures of the Coracoid Process," The Journal of Bone and Joint Surgery, Vol. 77, 1995, pp. 425-428.

[30] K. Ogawa, A. Yoshida, M. Takahashi and M. Ui, "Fractures of the Coracoid Process," The Journal of Bone and Joint Surgery, Vol. 79, No. 1, 1997, pp. 17-19. doi:10.1302/0301-620X.79B1.6912

[31] A. Steindler, "Traumatic Deformities and Disabilities of the Upper Extremity,” Thomas, Springfield, 1946, pp. 112118.

[32] J. Benson and C. Nelson, "Avulsion of Coracoid Process in an Athlete," The Journal of Bone and Joint Surgery, Vol. 53, 1971, pp. 356-358. 